\title{
Factors associated with second eye cataract surgery
}

\author{
Xavier Castells, Jordi Alonso, Cristina Ribó, Daniel Nara, Albert Teixidó, Miguel Castilla
}

\begin{abstract}
Aims-To analyse the clinical and sociodemographic characteristics associated with second eye cataract surgery.

Methods-An observational, longitudinal study of patients scheduled for first eye cataract surgery that did not involve a combined procedure was carried at two teaching hospitals and one non-teaching hospital in Barcelona, Spain. Patients were followed for 2 years after first eye cataract surgery to assess whether and when they had undergone second eye cataract surgery. Clinical characteristics, perceived health characteristics (perceived visual function and overall health status), and sociodemographic characteristics were compared between two patient groups-those with surgery in only one eye and those who had undergone surgery in both eyes by the end of the 2 year follow up period.
\end{abstract}

Results-Of the 242 patients studied, 125 $(51.7 \%)$ underwent second eye surgery during the 2 year observation period. Patients with visual acuity $6 / 18(0.3)$ or worse in the second eye compared with those with visual acuity over $6 / 12(0.5)$ and patients younger than 65 years compared with patients aged 65-74 were more likely to undergo second eye surgery (adjusted odds ratio 3.9 and 1.8 , respectively). 52 $(44.5 \%)$ patients in the only one eye surgery group had a visual acuity less than $6 / 18(0.3)$ in the second eye.

Conclusions-Worse visual acuity in the second eye and younger ages are strongly associated with both eyes cataract surgery. There may be a potential increase of demand for this procedure in the near future since almost half of the patients with only one eye surgery presented a low visual acuity in the second eye.

(Br f Ophthalmol 2000;84:9-12)

Cataract surgery is the most frequent surgical procedure performed among the elderly in the developed countries, and it has undergone an important increase in recent years. ${ }^{12}$ It is estimated that in the USA, ${ }^{34} \mathrm{UK}^{5}{ }^{6}$ and Sweden ${ }^{7}$ only one third of patients who have had first eye surgery subsequently undergo second eye surgery during the following 12 months. But available studies show an improvement in visual function and in stereoacuity after second eye surgery and suggest that better outcomes be achieved if patients undergo surgery in both eyes. ${ }^{4-13}$

Debate over the need for second eye surgery is influenced by the growing demand for cata- ract surgery, at times accompanied by long waiting lists. The significant cost associated with the possible generalisation of second eye surgery has led some medical insurance companies and national health services to give higher priority to first eye surgery than to that of the second eye. ${ }^{24714}$

The Agency for Health Care Policy and Research ${ }^{15}$ and other authors ${ }^{16}$ have concluded that surgery in the second eye should be recommended, specifically among patients who need good binocular vision. Some authors also have suggested that the decision to operate on the second eye is influenced by the patient's perceived need of surgery, and by social expectations. ${ }^{17}$ But there are no studies assessing specifically the decision related to second eye surgery. More evidence about the cost effectiveness of second eye surgery and the factors associated with the decision to perform this surgery is needed. The objective of the present study was to analyse the clinical, perceived health and sociodemographic characteristics associated with second eye cataract surgery.

\section{Patients and methods}

SETTING AND PATIENTS

Patients from the ophthalmology departments of two teaching hospitals and one non-teaching public hospital in Barcelona, Spain, were considered eligible if they were scheduled for first eye cataract surgery not involving a combined procedure, and met inclusion criteria for outpatient surgery. The care of all patients included in the study was funded by the state (Spanish national health services), and generally the patients had been referred from primary health care to hospital in order to assess the need of surgery.

Patients were included in the study during the index visit to the ophthalmologist, with recruitment taking place between April 1993 and January 1994. Patients were followed up for 2 years after surgery to assess whether and when they had undergone second eye surgery.

\section{STUDY VARIABLES}

Study ophthalmologists completed standardised clinical data forms with information related to visual acuity, ocular and medical comorbidity, and surgical complications. Clinical assessments were carried out preoperatively (baseline) and perioperatively and 4 months postoperatively after the first eye and the second eye surgery, if performed.

Besides clinical information, all patients were interviewed by telephone before and 4 months after first eye surgery in order to collect information on perceived visual function (the VF-14 index), cataract related symptoms, and 
overall perceived health status (the Sickness Impact Profile). The VF-14 index, ${ }^{18}{ }^{19}$ is a questionnaire that asks patients about the degree of difficulty experienced in carrying out 14 activities potentially related to vision (for example, reading small print, watching TV, day and night driving). Patients were also asked about their expectations of improvement in each of the 14 items. This permitted calculation of the proportion of patients experiencing as much improvement in their ability to

Table 1 Sociodemographic characteristics of the two groups of patients (with one eye only and both eyes cataract surgery), at the moment of their first eye surgery

\begin{tabular}{|c|c|c|c|c|c|}
\hline & \multicolumn{2}{|c|}{$\begin{array}{l}\text { One eye only surgery } \\
(n=117)\end{array}$} & \multicolumn{2}{|c|}{$\begin{array}{l}\text { Both eyes surgery } \\
(n=125)\end{array}$} & \multirow[b]{2}{*}{ p Value } \\
\hline & $n$ & $(\%)$ & $n$ & $(\%)$ & \\
\hline \multicolumn{6}{|l|}{ Age } \\
\hline$<65$ years & 26 & $(22.6)$ & 45 & $(36.6)$ & \\
\hline $65-74$ years & 40 & $(34.8)$ & 40 & $(32.5)$ & \\
\hline$\geqslant 75$ years & 49 & $(42.6)$ & 38 & (30.9) & 0.05 \\
\hline Mean age (SD) & 70.7 & (11.9) & 68.9 & $(10.8)$ & 0.06 \\
\hline Sex (males) & 54 & $(46.2)$ & 60 & $(48.0)$ & 0.77 \\
\hline Marital status (married) & 77 & $(65.8)$ & 87 & $(69.6)$ & 0.53 \\
\hline Educational ( $\geqslant 8$ years) & 13 & (11.1) & 13 & (10.4) & 0.88 \\
\hline Lives on his/her own & 17 & $(14.5)$ & 14 & $(11.2)$ & 0.44 \\
\hline Driving & 21 & $(17.9)$ & 22 & $(17.6)$ & 0.94 \\
\hline Working & 5 & $(4.9)$ & 11 & $(9.9)$ & 0.16 \\
\hline Hospital (teaching) & 90 & $(76.9)$ & 107 & $(85.6)$ & 0.08 \\
\hline
\end{tabular}

Table 2 Clinical characteristics of the two groups of patients (with one eye only and both eyes cataract surgery), at the moment of their first eye surgery

\begin{tabular}{|c|c|c|c|c|c|}
\hline & \multicolumn{2}{|c|}{$\begin{array}{l}\text { One eye only } \\
\text { surgery }(n=117)\end{array}$} & \multicolumn{2}{|c|}{$\begin{array}{l}\text { Both eyes } \\
\text { surgery }(n=125)\end{array}$} & \multirow[b]{2}{*}{ p Value } \\
\hline & $n$ & $(\%)$ & $n$ & $(\%)$ & \\
\hline \multicolumn{6}{|l|}{ Preoperative visual acuity in the operated eye } \\
\hline better than $6 / 18$ & 5 & $(4.3)$ & 6 & $(4.8)$ & \\
\hline $6 / 30$ to $6 / 18$ & 32 & $(27.4)$ & 32 & $(25.6)$ & \\
\hline $6 / 60$ or worse & 80 & $(68.4)$ & 87 & $(69.6)$ & 0.94 \\
\hline \multicolumn{6}{|l|}{ Preoperative visual acuity in the fellow eye } \\
\hline better than $6 / 12$ & 36 & $(30.8)$ & 8 & $(6.4)$ & \\
\hline $6 / 15$ to $6 / 12$ & 29 & $(24.8)$ & 18 & $(14.4)$ & \\
\hline $6 / 30$ to $6 / 18$ & 32 & $(27.4)$ & 65 & $(52.0)$ & \\
\hline $6 / 60$ or worse & 20 & $(17.1)$ & 34 & $(27.2)$ & $<0.001$ \\
\hline \multicolumn{6}{|l|}{ Postoperative visual acuity in the operated eye } \\
\hline better than $6 / 9$ & 32 & $(27.8)$ & 35 & $(28.0)$ & \\
\hline $6 / 10$ to $6 / 9$ & 41 & $(35.7)$ & 36 & $(28.8)$ & \\
\hline $6 / 15$ to $6 / 12$ & 22 & $(19.1)$ & 25 & $(20.0)$ & \\
\hline $6 / 18$ or worse & 20 & (17.4) & 29 & $(23.2)$ & 0.59 \\
\hline Patients with ocular comorbidity & 37 & $(31.6)$ & 46 & $(36.8)$ & 0.40 \\
\hline Diabetic retinopathy & 4 & (3.4) & 5 & $(4.0)$ & 0.81 \\
\hline Glaucoma & 7 & $(6.0)$ & 7 & $(5.6)$ & 0.90 \\
\hline Age related macular degeneration & 10 & $(8.5)$ & 9 & $(7.2)$ & 0.70 \\
\hline Patients with complications of surgery & 28 & $(23.9)$ & 28 & $(22.4)$ & 0.78 \\
\hline
\end{tabular}

Table 3 Perceived health measures of the two groups of patients (with one eye only and both eyes cataract surgery), at the moment of their first eye surgery

\begin{tabular}{|c|c|c|c|c|c|}
\hline & \multicolumn{2}{|c|}{$\begin{array}{l}\text { One eye only surgery } \\
(n=117)\end{array}$} & \multicolumn{2}{|c|}{$\begin{array}{l}\text { Both eyes surgery } \\
(n=125)\end{array}$} & \multirow[t]{2}{*}{$p$ Value } \\
\hline \multicolumn{5}{|l|}{ Preoperative } & \\
\hline $\begin{array}{l}\text { Mean Cataract Symptom Score } \\
(\mathrm{SD})^{\star}\end{array}$ & 3.8 & $(3.0)$ & 5.0 & $(3.4)$ & $<0.01$ \\
\hline Mean VF-14 score (SD) $\dagger$ & 68.9 & $(26.0)$ & 56.2 & $(23.6)$ & $<0.001$ \\
\hline $\begin{array}{l}\text { Mean Sickness Impact Profile score } \\
\text { (SD) } \ddagger\end{array}$ & 11.5 & $(9.8)$ & 12.5 & $(11.1)$ & 0.53 \\
\hline \multicolumn{6}{|l|}{ Postoperative } \\
\hline $\begin{array}{l}\text { Mean Cataract Symptom Score } \\
(\mathrm{SD})^{\star}\end{array}$ & 0.7 & $(1.7)$ & 0.7 & $(1.4)$ & 0.59 \\
\hline Mean VF-14 score (SD)† & 90.0 & $(20.1)$ & 87.1 & (19.3) & 0.11 \\
\hline $\begin{array}{l}\text { Expectations about VF-14 score } \\
(\%)^{\star \star}\end{array}$ & 70 & $(60.0)$ & 71 & $(56.8)$ & 0.62 \\
\hline $\begin{array}{l}\text { Mean Sickness Impact Profile score } \\
\text { (SD) } \ddagger\end{array}$ & 9.2 & $(9.1)$ & 8.1 & $(8.4)$ & 0.50 \\
\hline
\end{tabular}

${ }^{\star}$ Range $(0,15)$. Higher score indicates more symptoms.

†Range $(0,100)$. Higher score indicates better function.

$\ddagger$ Range $(0,100)$. Higher score indicates more dysfunction.

$\star \star$ Proportion of patients experiencing as much improvement in their ability to perform activities

as they expected preoperatively. perform activities as they had expected preoperatively, as other authors have proposed..$^{20}$ The cataract symptom score identifies the degree of discomfort caused by five symptoms that are common among cataract patients. Overall perceived health status was assessed with the Sickness Impact Profile (SIP), ${ }^{21}{ }^{22}$ a questionnaire consisting of 136 items, which measures sickness related dysfunction.

All patients were assessed whether and when they had undergone second eye surgery during the 2 years after the operation on the first eye based on a medical records review, except for 15 patients in which information was obtained through a telephone interview.

\section{ANALYSIS}

Patients were analysed in two groups: those with surgery in only one eye and those who had undergone surgery in both eyes by the end of the 2 year follow up period. These groups were compared at the time of the first eye cataract surgery, using the $t$ test procedure for normally distributed quantitative variables, and the Mann-Whitney test for non-normal variables. Fisher's exact test was applied for comparing proportions. A multivariate logistic regression model was built to identify factors associated with second eye surgery adjusting for the presence of other variables: type of hospital, age, employment status, visual acuity, ocular comorbidities, visual function, cataract symptoms, and perceived health status.

\section{Results}

Initially 285 patients were included in the study, of whom 43 were lost to follow up $(15.1 \%): 36$ refused the interview, five could not be contacted, and two patients had died by the end of the follow up period. Hence, information was available for a total of 242 patients. Of these, $125(51.7 \%)$ had undergone second eye surgery during the 2 year observation period. All 125 patients were operated in the same hospital where they had the first eye surgery. The median time between both interventions was 9 months. Twenty two per cent of the patients had undergone their second intervention within 6 months of the first one and only a $4 \%$ after 18 months.

For the first eye surgery, the surgical procedure used was standard extracapsular extraction with intraocular lens (IOL) implantation for all patients. Surgery in the second eye was performed with phacoemulsification in $44 \%$ patients because this technique was introduced in the hospitals during the study. Viscoelastic material, an intraocular miotic, and local anaesthesia were used for all patients. There were no differences between the two patient groups regarding sociodemographic characteristics except for age, which was higher in the "one eye only" surgery group (Table 1). At baseline, the "both eyes surgery" group had lower visual acuity in the fellow eye (or second eye): $79.2 \%$ of the patients had a visual acuity of $6 / 18$ or lower in the fellow eye compared with $44.5 \%$ in the one eye surgery group $(p<0.001)$. No other clinical differences were observed between the two groups (Table 2). 
Table 4 Patient characteristics associated with cataract surgery in both eyes, estimated through logistic regression $(n=210)$

\begin{tabular}{|c|c|c|c|c|c|}
\hline \multirow[b]{2}{*}{ Age } & \multirow[t]{2}{*}{ No } & \multirow[t]{2}{*}{$\begin{array}{l}\% \text { both eyes } \\
\text { surgery }\end{array}$} & \multicolumn{3}{|c|}{ Adjusted odds ratio C.I. (95\%) } \\
\hline & & & & & \\
\hline$\leqslant 64$ years & 64 & 62.5 & 1.83 & 1.05 & 3.19 \\
\hline $65-74$ years & 70 & 51.4 & Reference & & \\
\hline$\geqslant 74$ years & 76 & 46.1 & 0.60 & 0.37 & 0.97 \\
\hline \multicolumn{6}{|l|}{ Working } \\
\hline No & 194 & 51.5 & Reference & & \\
\hline Yes & 16 & 68.8 & 1.18 & 0.59 & 2.36 \\
\hline \multicolumn{6}{|l|}{ Teaching hospital } \\
\hline Yes & 170 & 55.9 & Reference & & \\
\hline No & 40 & 40.0 & 0.71 & 0.46 & 1.09 \\
\hline \multicolumn{6}{|l|}{ Ocular comorbidity } \\
\hline At least one & 74 & 55.4 & Reference & & \\
\hline No & 136 & 51.5 & 1.04 & 0.73 & 1.48 \\
\hline \multicolumn{6}{|c|}{ Visual acuity in the fellow eye } \\
\hline Better than $6 / 12$ & 39 & 17.9 & Reference & & \\
\hline $6 / 15$ to $6 / 12$ & 41 & 39.0 & 1.09 & 0.62 & 1.91 \\
\hline $6 / 18$ or worse & 130 & 67.7 & 3.92 & 2.40 & 6.40 \\
\hline \multicolumn{6}{|c|}{ Visual acuity in the operated eye (1) } \\
\hline Better than $6 / 12$ & 127 & 51.2 & Reference & & \\
\hline $6 / 15$ to $6 / 12$ & 41 & 51.2 & 0.83 & 0.48 & 1.44 \\
\hline $6 / 18$ or worse & 42 & 59.5 & 1.29 & 0.70 & 2.39 \\
\hline \multicolumn{6}{|c|}{ Cataract Symptom Score ${ }^{\star}(1)$} \\
\hline 1 & 173 & 53.2 & Reference & & \\
\hline $2-4$ & 31 & 54.8 & 1.28 & 0.44 & 3.03 \\
\hline 4 & 6 & 33.3 & 0.59 & 0.15 & 2.26 \\
\hline \multicolumn{6}{|l|}{ VF-14 score $†(1)$} \\
\hline$>95$ & 122 & 48.4 & Reference & & \\
\hline $71-95$ & 61 & 60.7 & 1.31 & 0.77 & 2.23 \\
\hline$\leqslant 70$ & 27 & 55.6 & 0.83 & 0.39 & 1.76 \\
\hline \multicolumn{6}{|l|}{ SIP score $\ddagger(1)$} \\
\hline$\leqslant 10$ & 141 & 55.3 & Reference & & \\
\hline $11-30$ & 44 & 52.3 & 1.07 & 0.60 & 1.89 \\
\hline$>30$ & 25 & 40.0 & 0.65 & 0.32 & 1.30 \\
\hline
\end{tabular}

(1) Postoperative period after first eye cataract surgery.

$\star$ Range $(0,15)$. Higher score indicates more symptoms.

† Range $(0,100)$. Higher score indicates better function.

$\ddagger$ Range $(0,100)$. Higher score indicates more dysfunction

Patients with surgery in both eyes presented worse perceived visual function before first eye surgery: cataract symptom score (5.0 $v 3.8$; $\mathrm{p}<0.01)$ and VF-14 (56.2 $v 68.9 ; \mathrm{p}<0.001)$ (Table 3). These differences disappeared 4 months after the first surgery. Perceived health status, as measured by SIP scores, was similar for the two groups before and after first eye surgery.

In Table 4 the adjusted odds ratios (ORs) of undergoing second eye surgery associated with all the variables studied are presented. Only visual acuity in the fellow eye before first eye

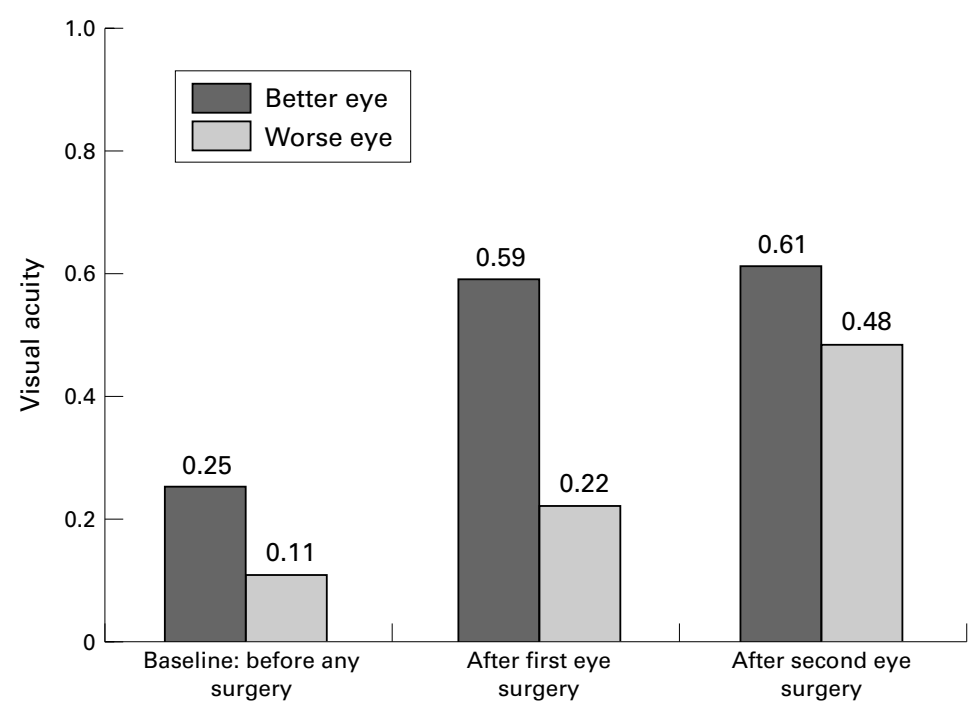

Figure 1 Visual acuity (on a decimal scale) in the better and worse eye among patients who underwent cataract surgery in both eyes $(n=125)$. surgery and age at baseline were significantly associated with second eye surgery. Specifically, patients with visual acuity $6 / 18$ or lower (0.3) were nearly four times more likely to undergo second eye surgery compared with those with visual acuity over $6 / 12(0.5)(\mathrm{OR}=$ 3.92; 95\% CI 2.40, 6.40). The adjusted odds ratio for patients younger than 65 years was 1.83 (95\% CI 1.05, 3.19), compared with those aged between 65 and 74, while for those over 74 years it was 0.60 (95\% CI $0.37,0.97)$.

Figure 1 shows the evolution of visual acuity (expressed on a decimal scale) in the better and worse eye among patients who underwent surgery in both eyes before any surgery (baseline), after first surgery, and after second eye surgery. It seems clear that after first eye surgery there was a significant improvement in visual acuity of the better eye, but not after second eye surgery. In contrast, visual acuity in the worse eye improved significantly after second eye surgery (visual acuity of 0.48 compared with 0.22 after first eye surgery; $\mathrm{p}<0.001$ ).

\section{Discussion}

More than one third of the patients in our study underwent second eye cataract extraction within 1 year of their first intervention, and more than half within 2 years. These percentages are similar to those reported in other studies. ${ }^{3-7}$

The results of our study indicate that the factor which most influences the decision to perform surgery in the second eye is the visual acuity of that eye, as is to be expected. However, the increase in visual acuity of the second eye after surgery did not produce a clinical relevant improvement in binocular vision acuity, since visual acuity in the better eye did not change. As suggested by Laidlaw and colleagues, ${ }^{8}$ second eye surgery improves mainly stereoacuity, probably because it reduces the differences between the visual acuities of the better and worse eyes. Although our study did not include specific stereoacuity measures, we have also observed that following surgery in the second eye the difference in visual acuity between better and worse eyes decreases (Fig 1).

According to our results visual acuity alone does not explain the decision to perform second eye surgery on a patient, since a third of the patients who presented a low visual acuity (6/18 or lower) did not finally undergo surgery. Age is another factor which presents a clear association with surgery. Thus, after adjusting for visual acuity the probability among the younger patients of undergoing second eye surgery was almost three times higher than among those aged over 74 years. On the other hand, having a paid job was also associated with a higher likelihood of second eye surgery, although the association did not reach statistical significance probably because of the small number of active patients in our study. These results suggest, as already pointed out by other authors, ${ }^{15} 16$ that the decision to perform second eye surgery is influenced by a greater need to recover binocular function, especially 
in the more socially active patients (younger patients or those who work).

Our results suggest that the patients who attended the teaching hospitals were more likely to undergo surgery in the second eye, although the difference was not statistically significant. A reason for this could be the higher activity and the need to teach residents on second eyes in the teaching hospitals.

An interesting finding of our study was that a sizeable fraction of patients with only one eye operated had a visual acuity in the second eye of $6 / 18$ or lower, a threshold for which the AHCPR ${ }^{15}$ recommended the indication of surgery in the second eye. Since this group of patients had no more ocular comorbidities which may affect the outcome of surgery, ${ }^{23}{ }^{24}$ other factors may have influenced the decision of not undergoing second eye surgery. We speculate that it was based on their older age and/or their lower perceived need to improve visual function. But this would not be justified since Javitt et al have observed ${ }^{4}$ that the improvement in visual function following second eye surgery is similar in the different age groups. Although other factors that may influence the decision to perform second eye surgery have not been analysed here, our results suggest that an important proportion of one eye only surgery patients may benefit from second eye surgery.

In spite of long waiting times in the public hospitals, and specifically in the three hospitals included in our study for all patients with surgery in both eyes, the second eye surgery was performed in the same hospital as the first one. These results are consistent with other studies where only $2 \%$ of patients scheduled for cataract surgery in public hospitals in Barcelona (also in Denmark and Manitoba) jumped the queue to private hospitals to reduce waiting times. ${ }^{25}$

The rate of second eye surgery observed in our study is similar to that of other countries, ${ }^{3-7}$ and, probably, it is lower than it would be expected based on the recommendations of the AHCPR guidelines ${ }^{15}$ and the results of recent studies which demonstrate a benefit from second eye surgery. ${ }^{8}$ The increasing demand for cataract surgery and the long waiting lists have led to a need to introduce criteria of prioritisation, very likely in favour of first eye surgery. Such criteria are based, among other factors, on the visual acuity of the better eye, which in practice is equivalent to giving priority to first eye surgery. ${ }^{714}$ A more appropriate prioritisation strategy should be based on the evidence about the cost effectiveness of second eye surgery in relation to first eye surgery. Such evidence does not exist yet and should be pursued. We thank the ophthalmology teams of Hospital de l'Esperança,
Hospital de Mataró, and Hospital General de la Vall d'Hebron. We especially appreciate the support of Dr Miquel Badia, chief We especially appreciate the support of Dr Miquel Badia, chief
of the ophthalmology department of Hospital de Mataró. We of the ophthalmology department of Hospital de Mataró. We
also thank Mercè Comas, statistician and data management also thank
Contributors: XC was the principal investigator and was responsible of the design, development and analysis of the study; JA actively intervened in the design, analysis and in the writing of the manuscript; CR, epidemiologist, was responsible for the study conduct completion and data analysis; DN was an examining ophthalmologist and in charge of clinical standardisation; AT was the statistician performing the analysis of data; $\mathrm{MC}$ was one of the examining ophthalmologists and responsible of general clinical results assessment.

Funding: Supported by a grant from the Fondo de Investigaciones Sanitarias (FIS) (Expte No 96/1569), Madrid, Spain, and from the Catalan Agency for Health Technology Assessment (CAHTA), Spain (17/33/97). Additional support was received from the government of Catalonia (CIRIT 1997 SGR 00359).

1 Rutkow IM. Surgical operations in the United States. Then (1983) and now (1994). Arch Surg 1997;132:983-90.

2 Nuffield Institute for Health, University of Leeds and NHS Centre for Reviews and Dissemination. Bulletin: manageCentre for Reviews and Dissemination. Bulletin: m
ment of cataract. Effective Health Care 1996;2:1-11.

3 Katz J, Schein OD, Tielsch JM, et al. Effect of a randomizing second eye in a trial to evaluate preoperative medical testing for cataract surgery. Ophthalmol Epidemiol 1997;4: $101-5$.

4 Javitt JC, Steinberg EP, Sharkey P, et al. Cataract surgery in one eye or both. A billion dollar per year issue. Ophthalmology 1995;102:1583-93.

5 Courtney P. The national cataract survey: I method and descriptive features. Eye 1992;6:487-92.

6 Claridge KG, Francis PJ, Bates AK. Should second eye surgery be rationed? Eye 1995;9:47-9.

7 Hanning $M$, Lundström M. Assessment of the maximum waiting time guarantee for cataract surgery: the case of a Swedish policy. Int $\mathcal{F}$ Technol Assess Health Care 1998;14: 180-93.

8 Laidlaw DAH, Harrard RA, Hopper CD, et al. Randomised trial of effectiveness of second eye cataract surgery. Lancet 1998;352:925-9.

9 Elliott DB, Patla A, Bullimore MA. Improvements in clinical and functional vision and perceived visual disability after first and second eye cataract surgery. $\mathrm{Br} \mathcal{F}$ Ophthalmol 1997;81:889-95.

10 Javitt JC, Brenner MH, Curbow B, et al. Outcomes of cataract surgery. Improvement in visual acuity and subjective visual function after surgery in the first, second and both eyes. Arch Ophthalmol 1993;111:686-91.

11 Laidlaw A, Harrard R. Can second eye cataract extraction be justified? Eye 1993;7:680-6.

12 Desai P, Reidy A, Minassian DC, et al. Gains from cataract surgery: visual function and quality of life. $\mathrm{Br} \mathcal{F}$ Ophthalmol 1996;80:868-73.

13 Castells X, Alonso J, Ribó C, et al. Comparison of the results of the first and second eye cataract surgery. Ophthalmology 1999;106:676-82.

14 Hadorn DC, Holmes AC. The New Zealand priority criteria project. Part 1: Overview. BMF 1997;314:131-4

15 Cataract Management Guideline Panel. Management of functional impairment due to cataract in adults. Rockville Maryland: US Dept of Health and Human Services, Public Health Service. Agency for Health Care Policy and Research, Rockville, Maryland, AHCPR Publication 93$0542,1993$.

16 Monestam E, Wachtmeister L. Impact of cataract surgery on car driving: a population based study in Sweden. $\mathrm{Br} f$ Ophthalmol 1997;81:16-22.

17 O'Day DM, Steinberg EP, Powe NR, et al. Methodology, management of functional impairment due to cataract in adults. Ophthalmology 1993;100;17S-21S

18 Steinberg EP, Tielsch JM, Schein OD, et al. The VF-14: an index of functional impairment in cataract patients. Arch Ophthalmol 1994;112:630-8.

19 Alonso J, Espallargues M, Folmer-Andersen $\mathrm{T}$, et al. International applicability of the VF-14, an index of visual function in patients with cataracts. Ophthalmology 1997; 104:799-807.

20 Tielsch JM, Steinberg EP, Cassard SD, et al. Preoperative functional expectations and postoperative outcomes among patients undergoing first eye cataract surgery. Arch Ophthalmol 1995;113:1312-18.

21 Bergner M, Bobbit RA, Carter WB, et al. The sickness impact profile: development and final revision of a health status measure: Med Care 1981;19:787-805

22 Badía X, Alonso J. Validity and reproducibility of the Spanish version of the sickness impact profile. $\mathcal{F}$ Clin Epidemiol 1996;49:359-65.

23 Lumme P, Laatikainen LT. Factors affecting the visual outcome after cataract surgery. Int Ophthalmol 1993;17:31317.

24 Schein OD, Steinberg EP, Cassard SD, et al. Predictors of outcome in patients who underwent cataract surgery. Ophthalmology 1995;102:817-23.

25 Anderson G, Black Ch, Dunn E, et al. Willingness to pay to shorten waiting time for cataract surgery. Health Affairs 1997;16:181-90. 